\title{
NUTRITIONAL INTERVENTIONS TO REDUCE STUNTING IN DEVELOPING COUNTRIES: A SYSTEMATIC REVIEW
}

\author{
Lasrika S Sinaga, Ciciilya Candi, Mardiati Nadjib \\ Masters Program in Public Health, Faculty of Public Health, \\ Universitas Indonesia
}

\begin{abstract}
Background: Childhood stunting remains a major malnutritional problem in developing countries. Stunting occurred the adverse effects on children's health in the short and long term, including failure to thrive, impairment of cognitive and motor development, stunted stature, metabolic disorders, and decreased intellectual capacity. Integrated nutritional intervention is important to prevent stunting. This study aimed to identify the nutritional interventions to reduce stunting in developing countries.

Subjects and Method: A systematic review was conducted by searching from Wiley Online Library, and ProQuest databases. The research question was formulated in PICO-S format: (1) Population, (2) Intervention, (3) Comparison, (4) Outcome, and (5) Study design. The next step was identification, screening, and checking the eligibility of the studies. The keywords were nutrition intervention and stunting reduction. The inclusion criteria were openly accessed and English-language articles published between 2019 to 2020. The searched articles were conducted identification, screening, and eligibility. The data were reported by PRISMA flow chart.

Results: Nine articles met the inclusion criteria. Integrated efforts to reduce stunting incidence were carried out through sensitive and specific nutritional interventions. A holistic approach involving the non-health sectors had significant impacts. Some limitations had still occurred in the capacity of implementing qualified nutritional interventions and their utilization.

Conclusion: Implementation of nutritional interventions have been focused in developing countries with different approaches to reduce stunting incidence.
\end{abstract}

Keyword: nutritional intervention, stunting, developing countries

\section{Correspondence:}

Lasrika S Sinaga. Masters Program in Public Health, Faculty of Public Health, Universitas Indonesia. Jl. Margonda Raya, Pondok Cina, Beji, Depok, 16424, East Java. Email: lasrikass20@gmail.com. Mobile: +62 81382375618. 